\title{
Effect of maternal mental health during pregnancy on infant growth at six months of age in Suburban communities in South of Iran
}

\author{
Hasan Ahmadi Gharaei ${ }^{1}$, Shahrzad Nematollahi ${ }^{1,2}$, Hossein Moameri ${ }^{1}$, Abdolhasan Madani ${ }^{3}$, Mahboubeh Parsaeian ${ }^{1}$, \\ Kourosh Holakouie-Naieni*1,4 (1)
}

Received: 13 Mar 2019

Published: 18 Nov 2020

\section{Abstract}

Background: Due to the controversial effects of mental health disorders during pregnancy on infant health, the present study aimed to evaluate the effect of gestational depression, stress, and anxiety on the growth of offspring at six months of age in disadvantaged communities in South of Iran.

Methods: The sample comprised of 470 pregnant women (response rate=98\%) who are participated in the Bandar Abbas Pregnancy Cohort study. Maternal mental health was measured by the DASS-21 questionnaire during pregnancy. Data on infant growth was collected based on infant's growth chart at six months of age. The relative risk of suboptimal infant growth was calculated by Modified Poisson regression models at $5 \%$ significant level.

Results: The prevalence of depression, anxiety, and stress was $19.0 \%, 26.1 \%$ and $6.5 \%$, respectively. At six months of age, the mean (SD) of infant's weight (gram), height $(\mathrm{cm})$ and head circumference $(\mathrm{cm})$ were $7287.30(1019.85), 63.23(5.62)$ and 41.39 (2.70), respectively. Compared to normal mothers, the risk of suboptimal weight at six months of age significantly increased by $71 \%$ in mothers who were classified as having depression (Adjusted RR: 1.71, 95\% CI: 1.07, 2.09). The presence of anxiety significantly increased the risk of suboptimal height at six months of age by $43 \%$ (ARR: $1.43,95 \%$ CI: $1.07,1.92$ ). There were no statistically significant effects of either depression anxiety or stress on the suboptimal head circumference at six months of age.

Conclusion: Our results showed that mental health disorders of pregnant women might adversely influence the weight and height growth of offspring within the first six months of age. Screening protocols to early diagnose of mental health disorders during pregnancy, and to strict follow up of diagnosed cases postpartum are proposed.

Keywords: Depressive disorders, Growth chart, Prospective studies, Community-participatory research

Conflicts of Interest: None declared

Funding: The National Institute for Medical Research Development (NIMAD) (Approval code: 943607).

\section{*This work has been published under CC BY-NC-SA 1.0 license. \\ Copyright $\odot$ Iran University of Medical Sciences}

Cite this article as: Ahmadi Gharaei H, Nematollahi Sh, Moameri H, Madani A, Parsaeian M, Holakouie-Naieni K. Effect of maternal mental health during pregnancy on infant growth at six months of age in Suburban communities in South of Iran. Med J Islam Repub Iran. 2020 (18 Nov);34:157. https://doi.org/10.47176/mjiri.34.157

Corresponding author: Dr Kourosh Holakouie-Naieni, holakoik@hotmail.com

1. Department of Epidemiology \& Biostatistics, School of Public Health, Tehran University of Medical Sciences, Tehran, Iran

2. Men`s Health and Reproductive Health Research Center, Shahid Beheshti University of Medical Sciences, Tehran, Iran

3. Department of Public Health, School of Public Health, Hormozgan University of Medical Sciences, Bandar Abbas, Iran

4. Bandar Abbas Health Research Station, School of Public Health, Tehran University of Medical Sciences, Bandar Abbas, Iran

\section{$\uparrow$ What is "already known" in this topic:}

One major consequence of maternal mental disorders might appear through missed antenatal visits, which leads to intrauterine growth retardation, frequent hospital admissions for infants, and increased risk of infant morbidities such as diarrhea and malnutrition.

\section{$\rightarrow$ What this article adds:}

- The prevalences of depression, anxiety, and stress in our study were lower than previous reports.

- Maternal depression during pregnancy has an effect on an infant's height at 6 months of age.

- Anxiety during pregnancy may lead to a $43 \%$ higher risk of stunting in 6-months old infants.

- The negative effects of maternal mental disorders on an infant's growth may be influenced by many social, cultural and behavioral factors. 


\section{Introduction}

Pregnancy is an important emotional experience, usually results in huge mental and physical changes in pregnant women. As a result, pregnant women are typically more susceptible to various mental disorders, including stress, depression, and anxiety compared to non-pregnant women (1). Nearly $10 \%$ and $13 \%$ of women experience depression either during or after pregnancy worldwide, respectively. This figure is even worse in the developing countries, as $15.6 \%$ of women in the pregnancy period and $19.8 \%$ of women in the post-partum period experience mental disorders (2). In addition to the adverse effects on maternal health, these psychological problems also can have adverse effects on infant health and family relationships. Affected mothers cannot carry out their responsibilities efficiently; as a result, the infant's growth may also be jeopardized (3).

Maternal mental health is influenced by various factors including advanced age, stressful occupations, high-risk pregnancy, history of abortion, unintended pregnancy and birth complications, and infant morbidities (4-6). One major consequence of maternal mental disorders might appear through missed antenatal visits, which leads to intrauterine growth retardation, frequent hospital admissions for infants, and increased risk of infant morbidities such as diarrhea and malnutrition (2).

Given the strong relationship between physical and mental health in pregnancy and it's negative effects on maternal and infant health, the provision of comprehensive antenatal care packages with the aim to maintain and improve mental health is highly warranted (7). In addition, mental disorders can be easily detected and treated, which justifies the necessity to take action against the problem. Despite the importance of maternal, newborn, and child health as one Sustainable Development Goal (SDG), most studies investigating the effects of maternal health during pregnancy on child development in Iran had a cross-sectional and retrospective nature. Therefore, the present study used data of a population-based prospective cohort study to evaluate the effects of maternal mental disorders during pregnancy on infant growth at the first six months of life in suburban neighborhoods of Bandar Abbas city during 2016-2017.

\section{Methods}

This study used the data from a population-based prospective cohort study entitled:" A population-based prospective study to identify contributors to mother and child health in suburban communities". The study, which is called henceforth "Bandar Abbas pregnancy cohort", was ethically approved and financially granted by National Institute for Medical Research Development (NIMAD) in 2016 (registration code: 943607) and is currently ongoing in the two most socially and economically vulnerable neighborhoods of Bandar Abbas city. The cohort sample consists of 1000 pregnant women who are residing in the study neighborhoods and had conception without medical interventions. Following recruitment in pregnancy, data were collected using interviews and evaluation of medical and healthcare records through four visits (pregnancy, 1, 6, and 12 months postpartum). The details of the methodology have been published elsewhere (8).

By the time of the present study, the data of 470 cohort subjects had been collected and were used for the analysis. Mental disorders during pregnancy were defined as the presence of depression, anxiety, and stress in the pregnancy and were measured using a 21-item DASS questionnaire (Depression, Anxiety, and Stress Scale). The questionnaire measures depression (seven questions, score range: 0-28), anxiety (seven questions, score range: 0-20), and stress (seven questions, score range: 0-34). The reliability and validity of this scale were previously confirmed in an Iranian population (9). It is worth mentioning that suspected cases of mental health problems following administrating the DASS questionnaire were advised to refer to a psychiatric counselor for further diagnosis and treatment.

Using child growth charts during the first 6-months of life, the outcome variables were defined as weight for age (in grams), height for age (in centimeter), and head circumference for age (in centimeter). The outcomes were further dichotomized based on below (suboptimal) and above (optimal) the red percentile (-2 SD) (7).

Socio-Economic Status of households (SES) was measured by Principal Component Analysis (PCA) on nine household properties (private car, motorcycle, freezer, dish-washer, microwave oven, PC or laptop computer, vacuum cleaner, washing machine, color TV (LCD/LED)) (10), and was named "asset". The asset variable was further dichotomized into poor or good SES based on the median.

For data analysis, we used chi-square for assessing the association between the qualitative variables. Predictors for the final model were selected in a backward selection scheme using a significance level of less than $20 \%$. Modified Poisson regression models were used to calculate relative risk (with $95 \% \mathrm{CI}$ ) of the effect of mental disorders on infant growth. Confounding variables were defined as those with a significance level below 0.2 (11) and were birth weight, infant infections, teething at 6 months for weight; birth height, infant's gender, SES, maternal occupation, and teething at 6 months for height; and birth rank, maternal occupation, and teething at 6 months for head circumference. All analyses were done using Stata version 14 (StataCorp, College Station, TX, USA) and GIS version 10.3. The significance level was set at $<0.05$.

\section{Results}

The mean (SD) age of the mothers was 27.24 (5.65) years (range: 16-42 years), while the majority were housewives $(n=453,96.38 \%)$ and had secondary/high school education $(n=264,56.17 \%)$. The results of the DASS showed that $16.49 \%(n=77)$ of the subjects were classified as having mental disorders. More specifically, 19\% $(n=89), 26.1 \%$ $(n=122)$, and $6.47 \%(n=30)$ of the subjects were classified as having depression, anxiety, and stress during pregnancy, respectively.

Boys comprised $53.62 \%(\mathrm{n}=252)$ of the newborns. Of all infants, $25.96 \%(n=122)$ were non-exclusively breastfed (including formula, cow's mild, or both), and $49.48 \%$ $(n=232)$ had at least one tooth at 6 months of age (Table 1). 
The mean (SD) of weight (in grams) was 3080 (900) at birth and $7287.30(1019.85)$ at six months of age. The mean (SD) of height (in centimeters) was 49.23 (3.14) at birth and 63.23 (5.62) at six months of age. The mean (SD) of head circumference (in centimeters) was 33.54 (2.14) at birth and 41.39 (2.70) at six months of age (Table 2).

The results of the modified Poisson regression model showed that compared to normal mothers, the risk of suboptimal weight at six months of age significantly increased by $71 \%$ in mothers who were classified as having depression (Adjusted RR: 1.71, 95\% CI: 1.07, 2.09). The presence of anxiety significantly increased the risk of suboptimal height at six months of age by $43 \%$ (ARR: 1.43 , $95 \% \mathrm{CI}: 1.07,1.92)$. On the other hand, there was no statistically significant effect of depression, anxiety or stress on the suboptimal head circumference at six months of age (Table 3).

Table 1. General characteristics of cohort subjects and their offspring in Suburban communities in the South of Iran, 2018

\begin{tabular}{|c|c|c|c|}
\hline Variable & Category & $\mathrm{N}$ & Relative frequency \\
\hline \multirow[t]{3}{*}{ Maternal education } & Illiterate/ reading \& writing & 128 & 27.23 \\
\hline & High school/ diploma & 264 & 56.17 \\
\hline & Academic & 78 & 16.60 \\
\hline \multirow[t]{2}{*}{ Maternal occupation } & Housekeeper & 453 & 96.38 \\
\hline & Staff & 17 & 3.62 \\
\hline \multirow[t]{2}{*}{ Current pregnancy } & Planned & 404 & 85.96 \\
\hline & Unplanned & 66 & 14.04 \\
\hline \multirow[t]{3}{*}{ Gestational trimester } & $1^{\text {st }}$ & 92 & 19.87 \\
\hline & $2^{\text {nd }}$ & 170 & 36.72 \\
\hline & $3^{\text {rd }}$ & 201 & 43.41 \\
\hline \multirow[t]{2}{*}{ Weight at birth (gram) } & $<2500$ & 195 & 41.49 \\
\hline & $>2500$ & 275 & 58.51 \\
\hline \multirow[t]{2}{*}{ Height at birth (cm) } & $<45$ & 38 & 8.09 \\
\hline & $\geq 45$ & 432 & 91.91 \\
\hline \multirow[t]{2}{*}{ Head circumference at birth (cm) } & $<33$ & 113 & 24.09 \\
\hline & $\geq 33$ & 356 & 75.91 \\
\hline \multirow[t]{2}{*}{ Infant feeding } & Breast milk & 348 & 74.04 \\
\hline & Other ${ }^{\gamma}$ & 122 & 25.96 \\
\hline \multirow[t]{2}{*}{ Multivitamin intake } & Regular & 422 & 89.79 \\
\hline & Irregular/Not used & 48 & 10.21 \\
\hline \multirow[t]{2}{*}{ infection contraction within 6-months } & No & 383 & 81.49 \\
\hline & Yes & 87 & 18.51 \\
\hline \multirow[t]{2}{*}{ Weight at 6-months } & Normal & 363 & 77.23 \\
\hline & Suboptimal & 107 & 22.77 \\
\hline \multirow[t]{2}{*}{ Height at 6-months } & Normal & 283 & 60.21 \\
\hline & Suboptimal & 187 & 39.79 \\
\hline \multirow[t]{2}{*}{ Head circumference at 6-months } & Normal & 264 & 56.17 \\
\hline & Suboptimal & 206 & 43.83 \\
\hline
\end{tabular}

$\gamma_{\text {including formula, cow`s milk, food, etc. }}$

Table 2. Distribution of maternal and infant characteristics according to infant growth at 6 months of age in Suburban communities in the South of Iran, 2018

\begin{tabular}{|c|c|c|c|c|c|c|c|c|c|c|}
\hline \multirow[b]{2}{*}{ Variable } & & \multicolumn{3}{|c|}{ Weight growth } & \multicolumn{3}{|c|}{ Height growth } & \multicolumn{3}{|c|}{ Head circumference } \\
\hline & & $\begin{array}{l}\text { Normal } \\
\text { N }(\%)\end{array}$ & $\begin{array}{c}\text { Sub- } \\
\text { Optimal } \\
\text { N (\%) }\end{array}$ & $\mathrm{p}$ & $\begin{array}{l}\text { Normal } \\
\text { N }(\%)\end{array}$ & $\begin{array}{c}\text { Sub-op- } \\
\text { timal N } \\
(\%)\end{array}$ & $\mathrm{p}$ & $\begin{array}{l}\text { Normal } \\
\text { N (\%) }\end{array}$ & $\begin{array}{l}\text { Sub-op- } \\
\text { timal N } \\
(\%)\end{array}$ & $\mathrm{p}$ \\
\hline \multirow[t]{5}{*}{$\begin{array}{l}\text { Maternal educa- } \\
\text { tion }\end{array}$} & $\begin{array}{c}\text { Illiterate/ El- } \\
\text { ementary }\end{array}$ & $\begin{array}{c}90 \\
(70.3)\end{array}$ & $\begin{array}{c}38 \\
(29.6)\end{array}$ & 0.047 & $\begin{array}{c}73 \\
(57)\end{array}$ & $\begin{array}{c}55 \\
(42.9)\end{array}$ & 0.120 & $\begin{array}{c}72 \\
(56.2)\end{array}$ & $\begin{array}{c}56 \\
(43.7)\end{array}$ & 0.550 \\
\hline & High school/ & 207 & 57 & & 155 & 109 & & 144 & 120 & \\
\hline & diploma & $(78.4)$ & $(21.6)$ & & $(58.7)$ & (41.3) & & $(54.5)$ & $(45.4)$ & \\
\hline & Academic & 66 & 12 & & 55 & 23 & & 48 & 30 & \\
\hline & & $(84.6)$ & $(15.3)$ & & $(70.5)$ & (29.4) & & $(61.5)$ & $(38.4)$ & \\
\hline \multirow{4}{*}{$\begin{array}{l}\text { Current preg- } \\
\text { nancy }\end{array}$} & Planned & 313 & 91 & 0.758 & 246 & 158 & 0.457 & 227 & 177 & 0.985 \\
\hline & & $(77.4)$ & $(22.5)$ & & $(60.8)$ & $(39.1)$ & & $(56.1)$ & $(43.8)$ & \\
\hline & Unplanned & 50 & 16 & & 37 & 29 & & 37 & 29 & \\
\hline & & $(75.7)$ & $(24.2)$ & & $(56)$ & (43.9) & & (56) & $(43.9)$ & \\
\hline \multirow[t]{4}{*}{ Infant sex } & Girl & 155 & 63 & 0.003 & 130 & 88 & 0.811 & 125 & 93 & 0.635 \\
\hline & & $(71.1)$ & $(28.9)$ & & $(59.6)$ & $(40.3)$ & & $(57.3)$ & $(42.6)$ & \\
\hline & Boy & 208 & 44 & & 153 & 99 & & 139 & 113 & \\
\hline & & $(82.5)$ & (17.4) & & $(60.7)$ & (39.3) & & $(55.1)$ & $(44.8)$ & \\
\hline \multirow{4}{*}{$\begin{array}{l}\text { exclusive breast } \\
\text { feeding }\end{array}$} & Yes & 274 & 74 & 0.190 & 213 & 135 & 0.457 & 198 & 150 & 0.592 \\
\hline & & (78.7) & $(21.2)$ & & (61.2) & (38.7) & & $(56.9)$ & $(43.1)$ & \\
\hline & No & 89 & 33 & & 70 & 52 & & 66 & 56 & \\
\hline & & (72.9) & (27) & & (57.3) & $(42.6)$ & & $(54.1)$ & (45.9) & \\
\hline \multirow[t]{4}{*}{ multivitamin } & Yes & 329 & 93 & 0.264 & 251 & 171 & 0.335 & 233 & 189 & 0.215 \\
\hline & & (77.9) & (22) & & (59.4) & $(40.5)$ & & $(55.2)$ & (44.8) & \\
\hline & No & 34 & 14 & & 32 & 16 & & 31 & 17 & \\
\hline & & $(70.8)$ & $(29.1)$ & & $(66.6)$ & (33.3) & & $(64.5)$ & $(35.4)$ & \\
\hline
\end{tabular}




\begin{tabular}{|c|c|c|c|c|c|c|c|c|c|c|}
\hline \multirow[b]{2}{*}{ Variable } & & \multicolumn{3}{|c|}{ Weight growth } & \multicolumn{3}{|c|}{ Height growth } & \multicolumn{3}{|c|}{ Head circumference } \\
\hline & & $\begin{array}{l}\text { Normal } \\
\text { N }(\%)\end{array}$ & $\begin{array}{c}\text { Sub- } \\
\text { Optimal } \\
\text { N (\%) }\end{array}$ & $\mathrm{p}$ & $\begin{array}{l}\text { Normal } \\
\text { N }(\%)\end{array}$ & $\begin{array}{c}\text { Sub-op- } \\
\text { timal N } \\
(\%)\end{array}$ & $\mathrm{p}$ & $\begin{array}{l}\text { Normal } \\
\text { N (\%) }\end{array}$ & $\begin{array}{c}\text { Sub-op- } \\
\text { timal N } \\
(\%) \\
\end{array}$ & $\mathrm{p}$ \\
\hline \multirow[t]{2}{*}{$\begin{array}{l}\text { Weight at birth } \\
\text { (gram) }\end{array}$} & $<2500$ & $\begin{array}{c}122 \\
(62.5)\end{array}$ & $\begin{array}{c}73 \\
(37.4)\end{array}$ & $<0.001$ & - & - & & - & - & \\
\hline & $\geq 2500$ & $\begin{array}{c}241 \\
(87.6)\end{array}$ & $\begin{array}{c}34 \\
(12.3)\end{array}$ & & - & - & & - & - & \\
\hline \multirow[t]{2}{*}{$\begin{array}{l}\text { Height at birth } \\
(\mathrm{cm})\end{array}$} & $<45$ & - & - & & $\begin{array}{c}20 \\
(52.6)\end{array}$ & $\begin{array}{c}18 \\
(47.3)\end{array}$ & 0.031 & - & - & \\
\hline & $\geq 45$ & - & - & & $\begin{array}{c}263 \\
(60.8)\end{array}$ & $\begin{array}{c}169 \\
(39.1)\end{array}$ & & - & - & \\
\hline \multirow{2}{*}{$\begin{array}{l}\text { Head circumfer- } \\
\text { ence at birth } \\
(\mathrm{cm})\end{array}$} & $<33$ & - & - & & - & - & & $\begin{array}{c}53 \\
(46.9)\end{array}$ & $\begin{array}{c}60 \\
(53.1)\end{array}$ & 0.024 \\
\hline & $\geq 33$ & - & - & & - & - & & $\begin{array}{c}210 \\
(58.9)\end{array}$ & $\begin{array}{l}146 \\
(41)\end{array}$ & \\
\hline \multirow[t]{2}{*}{ teeth } & No & $\begin{array}{c}178 \\
(74.4)\end{array}$ & $\begin{array}{c}61 \\
(25.5)\end{array}$ & 0.147 & $\begin{array}{c}143 \\
(59.8)\end{array}$ & $\begin{array}{c}96 \\
(40.1)\end{array}$ & 0.864 & $\begin{array}{r}134 \\
(56)\end{array}$ & $\begin{array}{c}105 \\
(43.9)\end{array}$ & 0.963 \\
\hline & Yes & $185(80)$ & $\begin{array}{c}46 \\
(19.9)\end{array}$ & & $\begin{array}{c}140 \\
(60.6)\end{array}$ & $\begin{array}{c}91 \\
(39.4)\end{array}$ & & $\begin{array}{c}130 \\
(56.2)\end{array}$ & $\begin{array}{c}101 \\
(43.7)\end{array}$ & \\
\hline \multirow{2}{*}{$\begin{array}{l}\text { infection con- } \\
\text { traction within } \\
6 \text {-months }\end{array}$} & no & $\begin{array}{c}311 \\
(81.2)\end{array}$ & $\begin{array}{c}72 \\
(18.8)\end{array}$ & $<0.001$ & $\begin{array}{c}232 \\
(60.5)\end{array}$ & $\begin{array}{c}151 \\
(39.4)\end{array}$ & 0.737 & $\begin{array}{c}213 \\
(55.6)\end{array}$ & $\begin{array}{c}170 \\
(44.4)\end{array}$ & 0.610 \\
\hline & Yes & $\begin{array}{c}52 \\
(59.7)\end{array}$ & $\begin{array}{c}35 \\
(40.2)\end{array}$ & & $\begin{array}{c}51 \\
(58.6)\end{array}$ & $\begin{array}{c}36 \\
(41.3)\end{array}$ & & $\begin{array}{c}61 \\
(58.6)\end{array}$ & $\begin{array}{c}36 \\
(41.3)\end{array}$ & \\
\hline \multirow[t]{2}{*}{ Depression } & No & $339(77)$ & $\begin{array}{c}101 \\
(22.9)\end{array}$ & 0.709 & $\begin{array}{c}265 \\
(60.22)\end{array}$ & $\begin{array}{c}175 \\
(39.77)\end{array}$ & 0.980 & $\begin{array}{c}247 \\
(56.1)\end{array}$ & $\begin{array}{c}193 \\
(43.8)\end{array}$ & 0.955 \\
\hline & Yes & $24(80)$ & $6(20)$ & & $18(60)$ & $12(40)$ & & $17(56.6)$ & $13(43.3)$ & \\
\hline \multirow[t]{2}{*}{ Anxiety } & no & $\begin{array}{c}299 \\
(76.6)\end{array}$ & $\begin{array}{c}91 \\
(23.3)\end{array}$ & 0.517 & $\begin{array}{c}235 \\
(60.2)\end{array}$ & $\begin{array}{c}155 \\
(39.7)\end{array}$ & 0.966 & $\begin{array}{l}225 \\
(57.7)\end{array}$ & $\begin{array}{c}165 \\
(42.3)\end{array}$ & 0.142 \\
\hline & yes & $64(80)$ & $16(20)$ & & $48(60)$ & $32(40)$ & & $39(48.6)$ & $41(51.2)$ & \\
\hline \multirow[t]{2}{*}{ Stress } & no & $\begin{array}{c}351 \\
(76.8)\end{array}$ & $\begin{array}{c}106 \\
(23.1)\end{array}$ & 0.189 & $\begin{array}{c}275 \\
(60.1)\end{array}$ & $\begin{array}{c}182 \\
(39.8)\end{array}$ & 0.921 & $\begin{array}{c}258 \\
(56.4)\end{array}$ & $\begin{array}{c}199 \\
(43.5)\end{array}$ & 0.460 \\
\hline & yes & $\begin{array}{c}12 \\
(92.3)\end{array}$ & $1(7.7)$ & & $\begin{array}{c}8 \\
(61.5)\end{array}$ & $5(38.4)$ & & $6(46.1)$ & $7(53.8)$ & \\
\hline
\end{tabular}

Table 3. Results of the modified Poisson regression model for the effect of depression, anxiety, and stress on anthropometric measures of a 6-months old infant in Suburban communities in the South of Iran, 2018

\begin{tabular}{|c|c|c|c|c|c|c|c|c|c|c|}
\hline \multirow[b]{2}{*}{ Exposure } & & \multicolumn{3}{|c|}{ Weight $^{\delta}$} & \multicolumn{3}{|c|}{ Height $^{¥}$} & \multicolumn{3}{|c|}{ Head circumference $^{\gamma}$} \\
\hline & & RR & $\begin{array}{l}\text { Lower } \\
\text { limit }\end{array}$ & $\begin{array}{l}\text { Upper } \\
\text { limit }\end{array}$ & RR & $\begin{array}{l}\text { Lower } \\
\text { limit }\end{array}$ & $\begin{array}{l}\text { Upper } \\
\text { limit }\end{array}$ & RR & $\begin{array}{c}\text { Lower } \\
\text { limit }\end{array}$ & $\begin{array}{c}\text { Upper } \\
\text { limit } \\
\end{array}$ \\
\hline \multirow[t]{2}{*}{ Depression } & No & & 1.00 & & & 1.00 & & & 1.00 & \\
\hline & Yes & 1.71 & 1.07 & 2.09 & 1.10 & 0.67 & 1.81 & 0.67 & 0.26 & 1.72 \\
\hline \multirow[t]{2}{*}{ Anxiety } & No & & 1.00 & & & 1.00 & & & 1.00 & \\
\hline & Yes & 1.76 & 0.82 & 3.76 & 1.43 & 1.07 & 1.92 & 0.74 & 0.48 & 1.69 \\
\hline \multirow[t]{2}{*}{ Stress } & No & & 1.00 & & & 1.00 & & & 1.00 & \\
\hline & Yes & 1.23 & 0.605 & 2.50 & 0.82 & 0.44 & 1.54 & 0.42 & 0.39 & 1.48 \\
\hline
\end{tabular}

${ }^{\delta}$ Adjusted for infant sex, having tooth at 6 months, birth weight, infection contraction within 6 months

${ }^{*}$ Adjusted for multivitamin intake, maternal education, birth height

${ }^{\gamma}$ Adjusted for infant sex, head circumference at birth, multivitamin intake

\section{Discussion}

In the present study, we found that $16.5 \%$ of pregnant women in suburban communities in Bandar Abbas were classified as having mental disorders. More specifically, the prevalence of depression, anxiety, and stress was calculated as $19 \%, 26.1 \%$ and $6.47 \%$, respectively. These values are found to be lower than what has been reported from previous reports among women in Iran $(25.6 \%-42.8 \%)(12,13)$. Moreover, the prevalence of anxiety in our study was substantially lower than what was reported previously from Bandar Abbas, (i.e., 42\%) (14). The observed discrepancy can be explained by using different instruments to measure mental health disorders and differences in study samples in terms of study setting and cultural context.

The mean weight, height, and head circumference of the infants at 6 months was $7.28(1.01) \mathrm{kg}, 63.23(5.62) \mathrm{cm}$, and $41.39(2.70) \mathrm{cm}$, respectively. The results of a study in infants below 2 years of age in Bandar Abbas showed a mean (SD) weight of $5.8(\mathrm{SD}=0.24)$ and $6.15(\mathrm{SD}=0.26) \mathrm{kg}$ and a mean height of $65(\mathrm{SD}=4.2)$ and $66.7(\mathrm{SD}=7.5) \mathrm{cm}$ in girls and boys aged 6 months, respectively (15). A comparison of the results shows that infants in our study weighed more than infants in other studies while there was no significant difference in height.

Similar to the results of the study by Katherine L. Wisner, our findings showed that maternal depression during pregnancy might affect infant growth, especially height, at 6 months (16). In the current study, the risk of stunting at 6 months in infants of mothers who had anxiety during pregnancy was $43 \%$ higher than its risk in infants of healthy 
mothers, while depression, stress and anxiety had no significant effect on weight and head circumference at 6 months. However, the results of a study by Kabiri et al. showed a significant correlation between maternal mental health and infant weight and head circumference at birth and two months (17). The results of another cohort study of 1200 mothers showed that maternal mental health during pregnancy had a direct effect on infant growth by six months and depression during pregnancy was associated with a decreased infant growth at 6 months (18). The possible mechanisms through which maternal depression affects infant growth and development may be an unhealthy lifestyle and reduced odds of follow-up on the necessary gestational and postpartum care. Depressed mothers are likely to allocate less time to their babies due to lack of energy, fatigue, and impatience, resulting in inadequate infant care. On the other hand, insufficient social support by family members and relatives, lower socio-economic status, lower education, and marital problems may also affect maternal mental health. Moreover, the mothers might be blamed for delivering a girl due to cultural reasons, which may worsen stress during pregnancy and hamper child development (12).

Anxiety, depression, and stress in pregnancy are risk factors for adverse outcomes for mothers and children. Anxiety in pregnancy is associated with shorter gestation and has adverse implications for fetal neurodevelopment and child outcomes. Anxiety about a particular pregnancy is especially potent. Chronic strain, exposure to racism, and depressive symptoms in mothers during pregnancy are associated with lower birth weight infants with consequences for infant development (5). Anxiety can also impact reproductive outcomes, such as the higher risk for preterm birth, LBW infants and fetal and infant neuro-development. Results of studies showed anxiety measured in pregnant women at the second and third trimesters predicted reduced and length. Anxiety during the third trimester predicted shorter gestational age (19-21). It is also reported that maternal anxiety has a significant impact on birth weight (19, $22,23)$, while in some other studies, significant differences between fetus's growth restriction, neonatal Apgar score, birth weight, birth length and head circumference among anxious and non-anxious women has not been reported (24). These risk factors can affect infant growth especially the height of the child.

Considering the relatively high prevalence of mental disorders during pregnancy and their adverse effects on the mother and infant, it is recommended that mothers undergo screening for mental disorders on the first prenatal visit and at the end of each semester. Moreover, it may be useful to study the effect of postpartum depression on infant growth in one year.

\section{Strength of the study}

The study used data from a population-based prospective cohort study. The prospective nature of the cohort study prevents misclassification and recall biases, while being population-based provides a wider spectrum of the target population for the results.

\section{Limitations}

Having measured mental health through questionnaire might have estimated the prevalence of mental health different from what it would be by clinical tests.

\section{Conclusion}

The results of this study showed a relatively high prevalence of anxiety and stress in pregnant women. Our study also showed that depression, anxiety, and stress could negatively affect infant health and growth at the year of life, especially in the first six months.

\section{Acknowledgment}

This study used data from the Bandar Abbas pregnancy cohort, which was ethically and financially supported by the National Institute for Medical Research Development (NIMAD) (Approval code: 943607). The authors would like to express their appreciation to the NIMAD for their valuable support and collaboration. We would also wish to thank all the study participants for their generous and sincere collaboration.

\section{Conflict of Interests}

The authors declare that they have no competing interests.

\section{References}

1. Cunningham FG, Leveno KJ, Bloom SL. Williams Obstetrics. 23 th ed. New York: McGraw-Hill; 2010.

2. World Health Organization. Maternal mental health WHO: WHO; 2018 [cited 2018 February]. Available from: http://www.who.int/mental health/mat ernal-child/maternal_men tal_health/en/.

3. Goedhart G, Snijders AC, Hesselink AE, von Poppel MN, Bonsel GJ, Vrijkotte GM. Maternal depressive symptoms in relation to perinatal mortality and morbidity: results from a large multiethnic cohort study. Psychosom Med. 2010;72:769-76.

4. Kheirabadi GR, Maracy MR. Perinatal depression in a cohort study on Iranian women. J Res Med Sci. 2010;15(1):41.

5. Schetter CD, Tanner L. Anxiety, depression and stress in pregnancy: implications for mothers, children, research, and practice. Curr Opin Psychiatry. 2012;25(2):141-8.

6. Lancaster CA, Gold KJ, Flynn HA, Yoo H, Marcus SM, Davis MM. Risk factors for depressive symptoms during pregnancy: a systematic review. Am J Obstet Gynecol. 2010;202(1):5-14.

7. World Health Organization. Child growth standards World Health Organization: World Health Organization; 2018 [cited 2018 November]. Available

https://www.who.int/childgrowth/standards/en/.

8. Holakouie-Naieni K, Nematollahi S, Mansournia MA, Shekari M, AghaMolayi T, Alavi A, et al. A Population-Based Prospective Study to Identify Contributors of Mother and Child Health in Suburban Communities: The Cohort Profile. Iran J Public Health. 2018;3.

9. Sahebi A, Asghary MJ, Salari R. Validation of Depression Anxiety and Stress Scale (DASS-21) for an Iranian Population. Iran J Psychiatry Behav Sci. 2005;1(4):299-310.

10. Filmer D, Scott K. Assessing Asset Indices. Demography. 2012;49:359-92.

11. Greenland S, Pearce N. Statistical Foundations for Model-Based Adjustments. Ann Rev Public Health. 2015;36:89-108.

12. Barjasteh S, Moghadam F. The relationship between the level of anxiety during pregnancy with spousal support and social support. Nurs Midwif J. 2016;14(6):504-15.

13. Zareipoor M, Sadeghi R, Bazvand E. Mental Health and Related Factors in Pregnant Women in Koohdasht Health Centers. Health Develop 2012;1(2):156-65.

14. Sadeghi N, Azizi S, Molaeinezhad M. Anxiety status in pregnant mothers at third trimester of pregnancy and its related factors in referrals to Bandar Abbas Hospitals in 2012. Iran J Obstet Gynecol Infertil. 2014;17(122):8-15. 
15. Hosseinzade K, Pormehr A, Rahmati R, Yousefi H. Comparing the growth of under 2 years old children referring to health centers of Bandar Abbas with NCHS standard curve. J Comprehen Nurs Mid. 2005;15(1):39-44

16. Wisner KL, Bogen DL, Sit D, McShea M, Hughes C, Rizzo D, et al. Does fetal exposure to SSRIs or maternal depression impact infant growth? Am J Psychiatry. 2013;70(5):485-93.

17. Kabiry B, Shahri P, Azarnosh S, Haghighizadeh M, Mirfathi S. The Relationship between Mother's General Health and Growth of below6-Month-Old Infants Referred to Health Centers of West of Ahvaz. Sadra Med Sci J. 2015;3(3):227-34

18. Traviss GD, West RM, House AO. Maternal mental health and its association with infant growth at 6 months in ethnic groups: results from the Born-in-Bradford birth cohort study. PloS One. 2012;7(2:e30707.).

19. Hosseini SM, Biglan MW, Larkby C, Brooks MM, Gorin MB, Day NL. Trait anxiety in pregnant women predicts offspring birth outcomes. Paediatr Perinat Epidemiol. 2009;23(6):557-66.

20. Glover V. Prenatal stress and its effects on the fetus and the child: possible underlying biological mechanisms. Perinatal programming of neurodevelopment: Springer; 2015. p. 269-83.

21. Broekman BF, Chan YH, Chong YS, Kwek K, Sung SC, Haley CL, et al. The influence of anxiety and depressive symptoms during pregnancy on birth size. Paediatr Perinat Epidemiol. 2014;28(2):11626.

22. Ding XX, Wu YL, Xu SJ, Zhu RP, Jia XM, Zhang SF, et al. Maternal anxiety during pregnancy and adverse birth outcomes: a systematic review and meta-analysis of prospective cohort studies. J Affect Disord. 2014;159:103-10

23. Schetter CD, Tanner L. Anxiety, depression and stress in pregnancy: implications for mothers, children, research, and practice. Curr Opin Psychiatry. 2012;25(2):141.

24. Shahhosseini Z, Abedian K, Azimi H. Role of anxiety during pregnancy in preterm delivery. J Adv Med Biomed Res. 2008;16(63):85-92. 